DOI:

http://dx.doi.org/10.15448/1983-4012.2015.2.18840

\title{
A ESTÉTICA KANTIANA: O BELO, O SUBLIME E A ARTE
}

The Kantian Aesthetic: Beauty, Sublime and Art

\section{Julie Christie Damasceno *}

Resumo: O presente artigo tem por finalidade investigar a estética kantiana, mais especificamente no que se refere à questão do belo, a presença do sublime na arte, a relação existente entre arte, liberdade e natureza, assim como também, a analogia entre gênio e natureza. Compreende-se a importância das conceituações estéticas kantianas como indispensáveis para se abordar a questão da arte, sobretudo porque o filósofo alemão sempre buscou relacionar a arte e as suas diversas manifestações à vida do homem. Para tanto, utilizar-se-á os textos kantianos Crítica da faculdade do juízo e Observaciones sobre el sentimiento de lo bello y lo sublime, além de textos de comentadores, a exemplo de Deleuze e Terra.

Palavras-chave: Estética. Belo. Sublime. Arte.

\begin{abstract}
This article aims to investigate the Kantian aesthetics, specifically with regard to the question of the beauty, the presence of the sublime in art, the relationship between art, nature and freedom, as well as the analogy between genius and nature. Understands the importance of the Kantian aesthetic concepts as necessary to address the question of art, especially since the German philosopher has always sought to relate art and its various manifestations to human life. For this purpose, shall be used-the Critique of judgment and Observaciones sobre el sentimiento de lo bello y lo sublime, as well as texts of commentators, like Deleuze and Terra.
\end{abstract}

Keywords: Aesthetic. Beauty. Sublime. Art.

* Discente do Programa de Pós-Graduação em Filosofia da Universidade Federal do Pará julychris2012@gmail.com

\begin{tabular}{|c|c|l|l|c|c|}
\hline intuitio & $\begin{array}{c}\text { ISSN } \\
1983-4012\end{array}$ & Porto Alegre & Vol.8 $-\mathrm{N}^{\circ} .2$ & $\begin{array}{c}\text { Dezembro } \\
2015\end{array}$ & p.146-158 \\
\hline
\end{tabular}




\section{Introdução}

Para a investigação da estética é imprescindível o estudo de Immanuel Kant na apresentação dos conceitos mais centrais e significativos no que se refere a esse campo. Tal comparecimento é mais do que justificado, uma vez que Kant empreendeu uma análise aprofundada da arte e sua composição enquanto presença inquestionável na vida do homem, apontando uma dupla diferenciação no que se refere à questão da arte, ou seja, um juízo de caráter estético e outro de natureza teórica.

$\mathrm{Na}$ arte, acentua-se o juízo de gosto, contudo esse mesmo juízo não consegue explicitar a finalidade com a qual um quadro, por exemplo, foi pintado. Sente-se o prazer estético diante desse quadro, como afirma Kant: "Logo, é na capacidade universal de comunicação do estado da mente na representação dada que, como condição subjetiva do juízo de gosto, deve estar fundamentado esse juízo e ter como consequência o prazer face ao objeto"1.

O objeto encerra em si a representação que, dependendo do indivíduo e de como ele é afetado pela obra de arte, resultará em uma sensação que geralmente está associada ao prazer e ao desprazer que tal objeto suscita, sendo que a sensação de prazer ou desprazer perante a obra de arte, mesmo que a princípio seja concebida como meramente atrelada ao gosto, deve ser considerada também pelo viés da pretensão de universalidade do sentimento de belo.

Em Crítica do Juízo Estético, Kant apresenta posicionamentos que marcaram definitivamente o estudo dos problemas estéticos, a "viragem para a Estética" assinala a importância da experiência estética, acentuando-se, dessa forma, a significância da Arte não apenas como uma forma de expressão, como algo que apenas serviria como meio de declaração da subjetividade humana, mas como parte significativa das afecções do espírito. Uma dessas afecções é o juízo de gosto que, como se pode depreender, não é inerente a um só homem ou a um grupo específico de indivíduos, mas sim algo que está presente em todos os seres humanos indistintamente. Considerar o gosto como um sentimento do belo, como por exemplo, observar uma escultura e ser afetado esteticamente por tal objeto, reforça a questão do juízo estético como algo que faz parte das faculdades da mente, em uma livre associação de ideias e sentimentos referentes a tal objeto, o que nos permite dizer que o juízo de gosto é também um exercício de liberdade.

Essa liberdade está associada à imaginação, uma vez que não se pode afirmar, conforme o pensamento de Kant, que o juízo de gosto esteja atrelado às funções reguladoras e também legisladoras das faculdades que compõem o pensamento do homem, mas também não se pode dizer que essa liberdade esteja desvinculada das faculdades intelectuais, uma vez que o juízo necessita dessas referidas faculdades

${ }^{1}$ KANT, Immanuel. Crítica da faculdade do juízo. Tradução de Valério Rohden e Antônio Marques. 2. ed. Rio de Janeiro: Forense Universitária, 1995, p. 61.

\begin{tabular}{|c|c|c|c|c|c|}
\hline intuitio & $\begin{array}{c}\text { ISSN } \\
1983-4012\end{array}$ & Porto Alegre & Vol.8- No.2 & $\begin{array}{c}\text { Dezembro } \\
2015\end{array}$ & p.146-158 \\
\hline
\end{tabular}


para a elaboração e aplicação da percepção estética que permitirá ao indivíduo dizer que tal objeto é belo ou não.

É de se supor que esse juízo de gosto, com base na filosofia de Kant, esteja intrinsecamente interligado com a questão da estética, uma vez que essa percepção do que agrada ou não ao homem, aquilo que lhe causa prazer ou desprazer, é possibilitado através desse juízo, que permite uma apropriação não corriqueira de um determinado objeto. É por causa desse juízo que diante de um dado objeto podemos ou não considerá-lo um objeto de arte. Isso ocorre porque a experiência estética não é um acontecimento vulgar, não é um fato corriqueiro que se efetua cotidianamente. Um pôr do sol, por exemplo, oferece ao homem uma experiência estética, contudo é importante frisar que um pôr do sol pode ser contemplado de diferentes maneiras dependendo de quem é o observador, um cientista não irá apreciar esse evento (pôr do sol) da mesma forma que um casal de namorados, pois aquele levará em consideração o fato de se tratar de um fenômeno que surge com o movimento de rotação da Terra, enquanto a este interessariam os sentimentos que tal evento pode suscitar. Isto porque é necessário o sentimento de prazer diante de tal espetáculo, sem esse sentimento não é possível desfrutar a experiência estética. Entretanto, esse prazer, essa sensação que arrebata o homem do seu cotidiano, não é uma satisfação meramente resultante de combinações sensoriais.

Nesse aspecto, pode-se dizer que o homem é afetado, esteticamente, tanto por objetos por si produzidos quanto os de origem natural. Mas essa experiência somente se efetua se no objeto ou na imagem vislumbrado não ocorrer algum interesse intermediando o contato entre o sujeito e o seu objeto de admiração, pois a arte, em si, não possui uma finalidade prática no sentido de produção, tal qual uma cadeira ou uma garrafa de água. O objeto de arte é apreciável por si mesmo e não pela facilidade ou utilidade que ele pode fornecer àquele que o contempla, nem pela compensação financeira que pode proporcionar. Outra característica da experiência estética é a seguinte: ela não é uma atitude que visa à aquisição de conhecimento.

A visão de um biólogo referente a uma flor certamente deve ser diferente da apreciação de dado homem quando este está experimentando um prazer estético diante da mesma flor. Se o biólogo enxergar tal flor sob o viés do conhecimento biológico, ou seja, a qual família e espécie, por exemplo, pertence tal flor, com certeza ele está afastando de si a experiência estética, que requer a contemplação pura e desinteressada para ocorrer.

Não é sem motivo que Kant, ao trabalhar as questões referentes à estética, não pretende estabelecer um sistema filosófico do belo nem elaborar teorias que encerrem ou pretendam dar conta de toda a complexidade da relação do homem com a arte. Seu intento basilar é compreender como juízos estéticos podem ser considerados válidos em um plano de proporções universais, ou seja, entender como uma obra de arte, cuja afecção estética está presente, afeta indivíduos de diferentes regiões, e não apenas

\begin{tabular}{|c|c|l|l|c|c|}
\hline intuitio & $\begin{array}{c}\text { ISSN } \\
1983-4012\end{array}$ & Porto Alegre & Vol.8 $-\mathrm{N}^{\mathrm{o} .2}$ & $\begin{array}{c}\text { Dezembro } \\
2015\end{array}$ & p.146-158 \\
\hline
\end{tabular}


isto, mas também de diferentes épocas, uma vez que o juízo estético permeia o julgamento do homem há muito, talvez não com esta nomenclatura, mas com similar característica. O que pode ocorrer, no decorrer da história da humanidade, são as sucessões de estilo, de diferenças de forma, de interpretação e visão da arte e de como esta afeta o homem, mas o juízo estético permanece, posto que se enquadre na concepção das faculdades inerentes ao pensamento do homem.

A estética está voltada para a questão do inteligível, que por sua vez, de alguma forma, conforme Kant, exerce influência também sobre o sensível. O inteligível, para Kant, atua sobre o homem como uma lei que não está submetida ao mundo sensível, às leis da natureza, por isso o inteligível não se fundamenta na experiência, na efetividade empírica, mas somente na razão. A atividade estética, contudo, não significa uma supressão da natureza em nome de uma liberdade humana criadora ou inventiva, mas sim a junção entre natureza e homem, uma vez que o homem estaria interligado com a natureza de modo indissociável no plano das realizações. A arte, dessa forma, apresenta-se, também, como um ato de libertação do homem, que se desvencilha da natureza, sob certo aspecto, e exerce sua atividade lúdica, despretensiosa, voltando-a para o prazer, diferentemente do oficio, como esclarece Kant:

A arte distingue-se também do "ofício"; a primeira chama-se "arte livre", a outra pode também chamar-se "arte remunerada". Olha-se a primeira como se ela puder ter êxito (ser bem sucedida) conforme a um fim somente enquanto jogo, isto é ocupação que é agradável por si própria; olha-se a segunda enquanto trabalho, isto é, ocupação que por si própria é desagradável (penosa) ${ }^{2}$.

Aqui se apresenta os traços de outro significativo conceito na filosofia kantiana, o belo, relacionado ao que é agradável e também de natureza desinteressada, cuja satisfação proporcionada não deve buscar outro fim além do prazer estético, apresentando um valor que seja universal e necessário. $\mathrm{O}$ objeto, portador da característica de belo, vale enquanto efeito de representação sobre o indivíduo e não pela sua existência material, física. O consumo do estético no objeto efetua-se de modo contemplativo, uma fez que a sua natureza, como obra de arte, é a de se doar à apreciação do seu observador.

\section{O belo na estética kantiana}

O belo, conforme Kant, não está relacionado ao deleitamento que o objeto pode vir ou não a proporcionar ao sujeito, assim como também não pode ser associado à concepção de que vem a ser, ou não, algo bom, uma vez que o belo independe de qualquer interesse considerado sensível - assim como da concepção de racional -, que queira situá-lo no campo puramente sensorial, ou seja, denominá-lo de bom,

${ }^{2}$ KANT, Immanuel. Crítica da faculdade do juízo. Tradução de Valério Rohden e Antônio Marques. 2. ed. Rio de Janeiro: Forense Universitária, 1995, p. 150.

\begin{tabular}{|c|c|l|l|c|c|}
\hline intuitio & $\begin{array}{c}\text { ISSN } \\
1983-4012\end{array}$ & Porto Alegre & Vol.8 $-\mathrm{N}^{\mathrm{o}} .2$ & $\begin{array}{c}\text { Dezembro } \\
2015\end{array}$ & p.146-158 \\
\hline
\end{tabular}


ou ruim. Diz-nos Kant: "aquilo que é puramente subjetivo na representação de um objeto, isto é, o que constitui a sua relação ao sujeito, e não ao objeto, é a sua qualidade estética”3.

Dessa forma, pode-se afirmar que o belo está desatrelado de qualquer tipo de conceituação que tente impor delimitações sob esses dois vieses, o do aprazível e do bom, posto que o sentimento de belo, ao proporcionar a experiência estética ao homem, faz com que este, por sua vez, não consiga definir com exatidão o seu sentimento diante da obra de arte que expressa o belo. A contemplação, desse modo, é uma espécie de livre satisfação que o indivíduo sente diante da obra de arte. Segundo Deleuze:

O juízo de gosto "é belo" exprime no espectador um acordo, uma harmonia de duas faculdades: imaginação e entendimento. Com efeito, se o juízo de gosto se distingue do juízo de preferência, é por que ele pretende uma certa necessidade, uma certa universalidade a priori. Ele toma do entendimento, portanto, sua legalidade. Mas esta legalidade não aparece aqui em conceitos determinados. A universalidade no juízo de gosto é aquela de um prazer; a coisa bela é singular, e permanece sem conceito ${ }^{4}$.

A imaginação reserva para si a posição de faculdade livre, pois ela não se encontra na posição de submissão em relação às outras faculdades que se apresentam mediante a intelectualidade, mas isso não significa dizer que essa liberdade é incondicional, uma vez que, ao considerar alguma coisa bela, tal imaginação, de alguma forma, estabelece com tal objeto uma relação mais complexa, de não distanciamento. No pensamento estético, a regra é contingente, isto é, se modifica, depende de escolhas e deliberações dos homens, em condições determinadas; o estético é um pensamento que não está previsto em uma regra. Portanto, o artista cria formas que nunca se repetem. Ainda sobre a imaginação, fala-nos Deleuze:

Kant chega a dizer que a imaginação, no juízo estético, "esquematiza sem conceito". Esta fórmula é mais brilhante do que exata. O esquematismo é um ato original da imaginação, mas com relação a um conceito determinado do entendimento. Sem conceito do entendimento, a imaginação faz outra coisa que esquematizar. Com efeito, ela reflete. É este o verdadeiro papel da imaginação no juízo estético: ela reflete a forma do objeto. Por forma, aqui, não se deve entender forma da intuição (sensibilidade) . $^{5}$

O belo, por sua vez, é a singularidade que não pode ser fechada em um conceito determinador, uma vez que um conceito é universal, e o que faz o artista? Cria obras que não podem ser repetidas, não

\footnotetext{
${ }^{3}$ KANT, Immanuel. Crítica da faculdade do juízo. Tradução de Valério Rohden e Antônio Marques. 2. ed. Rio de Janeiro: Forense Universitária, 1995, p. 49-50.

${ }^{4}$ DELEUZE, Gilles. A filosofia crítica de Kant. Tradução de Germiniano Franco. Lisboa/Portugal. Edições 70. 1963, p. 02.

${ }^{5}$ DELEUZE, Gilles. A filosofia crítica de Kant. Tradução de Germiniano Franco. Lisboa/Portugal. Edições 70. 1963, p. 06.
}

\begin{tabular}{|c|c|c|c|c|c|}
\hline intuitio & $\begin{array}{c}\text { ISSN } \\
1983-4012\end{array}$ & Porto Alegre & Vol.8 $-\mathrm{N}^{\circ} .2$ & $\begin{array}{c}\text { Dezembro } \\
2015\end{array}$ & p.146-158 \\
\hline
\end{tabular}


podem até mesmo ser copiadas, e aqui acionamos Walter Benjamim e o seu conceito de aura ${ }^{6}$. Essa não repetição da obra de arte se coaduna também com a percepção do belo, cuja experiência é diversa para cada um, ou seja, não há um sentimento em relação ao belo que possa ser denominado de idêntico ao que outra pessoa sente diante da obra de arte, por isso a complexidade de se buscar uma conceituação que abarque essa multiplicidade de percepções. O belo existe e se efetiva, inegavelmente, mas em medidas diferentes para cada indivíduo. A universalidade do fenômeno está na partilha desse sentimento de comunhão no que diz respeito ao belo, que se pode denominar de estado de alma, que, conforme a filosofia kantiana, seria o resultado da interação entre imaginação e entendimento referentes à obra de arte.

Mas o prazer que se sente nesse referido estado de alma não se encontra no objeto em si, mas na representação efetuada pelo sujeito, importante peça nesse processo estético, pois o objeto artístico é apreendido através das faculdades cognitivas que são acionadas no jogo estético e sua apreensão. É por isso que Kant evidencia a independência do juízo de gosto em relação ao conceito de perfeição ${ }^{7}$.

\section{A presença do sublime na arte}

É preciso, na continuidade do estudo sobre a estética em Kant, distinguir belo e sublime para o filósofo alemão, distinção essa que algumas vezes é ignorada por uma parcela dos estudiosos mais incautos de Kant: de modo bastante sintético, pode-se dizer que o belo possui uma ligação mais efetiva com o objeto sensível, enquanto que o sublime associa-se à razão. O belo se encontra delimitado pela limitação do objeto, não ocorrendo, dessa forma, um excesso que ultrapasse a própria obra de arte, o que já ocorre com o sublime, que está presente em um objeto destituído de forma delimitada nos moldes de um objeto de arte, o que possibilita que o sublime se encaminhe para o ilimitado, tal como se a razão não encontrasse limite definido. O sublime está relacionado à comoção no sentido de um sentimento violento, como se lê em nota de rodapé de Crítica da faculdade do juízo, tradução de Valério Rohden e António Marques:

O termo "rührung", ligado ao sentimento do sublime, significa uma emoção violenta, isto é uma comoção. Grimm (no seu "wõrterbuch" sob a variante 4), ao conferir a "rührung" o sentido de "mover interiormente, "commovere", remete ao próprio Kant, a propósito da sua afirmação de que o sublime comove enquanto o

\footnotetext{
${ }^{6}$ Livro: BENJAMIM, Walter. "A obra de arte na era de sua reprodutibilidade”. In: Magia e Técnica, arte e política ensaios sobre literatura e história da cultura. Obras escolhidas, volume I, $2^{a}$ edição, São Paulo: Editora Brasiliense, 1994, p. 170. Para o referido filósofo, aura seria aquilo que torna uma coisa singular, única: "Em suma, o que é a aura? É uma figura singular, composta de elementos espaciais e temporais: a aparição única de uma coisa distante, por mais perto que ela esteja".

${ }^{7}$ KANT, Immanuel. Crítica da faculdade do juízo. Tradução de Valério Rohden e Antônio Marques. 2. ed. Rio de Janeiro: Forense Universitária, 1995, p. 72.
}

\begin{tabular}{|c|c|c|c|c|c|}
\hline intuitio & $\begin{array}{c}\text { ISSN } \\
1983-4012\end{array}$ & Porto Alegre & Vol.8 $-\mathrm{N}^{\circ} .2$ & $\begin{array}{c}\text { Dezembro } \\
2015\end{array}$ & p.146-158 \\
\hline
\end{tabular}


belo atrai ("Das Erhabene rührt, das Schõne reitz"). A maioria das traduções, contrariamente, usou no caso apenas o termo "emoção"

Entre belo e sublime, e suas distinções ${ }^{9}$, apresentam-se variantes cruciais, uma vez que o primeiro liga a sua representatividade a um plano qualitativo, enquanto o segundo enquadra-se em uma determinação quantitativa. Mas observa-se que ambos possuem a capacidade de promover uma espécie de elevação espiritual no indivíduo, apesar de que o sublime se volta com intensidade para a questão do sentimento. A arte, assim posto, tem a força de promover no homem transformações de expressivo significado que pode ser situada no campo da religiosidade, e também da moral, uma vez que para Kant ambos estão interligados de modo indistinto, haja visto que a ética, segundo o filósofo germânico, enquadra-se no campo do dever, ou seja, age-se eticamente por necessidade.

O sublime, como se pode depreender, é aquilo que choca, que causa sentimentos vigorosos que se distinguem, tais como entusiasmo e medo. É possível senti-lo quando se está em uma situação de natureza incomum, mas grandiosa, cuja intensidade o homem tem uma pequena estimativa. Reale e Antisere descrevem os efeitos do sublime como sendo:

(...) um prazer que surge apenas indiretamente, ou seja, é produzido pelo sentido de um impedimento momentâneo, seguido de uma efusão mais forte das forças vitais e, por isso, enquanto emoção, não se apresenta de fato como um jogo, mas como algo de sério no emprego da imaginação ${ }^{10}$.

Assim posto, o sublime é aquilo que não pode ser medido, posto que se apresenta como uma potência que não é comensurável, estando acima do homem em força, poder e extensão. Mas justamente essa característica se configura como algo positivo ao homem, pois este desenvolve a consciência desse poder da razão que subtrai todas as medidas do sentido. É o que de certa forma busca o pintor, o poeta, o cantor, o artista, enfim, quando produz suas obras. Tenciona-se, em muitos casos, chocar, levar o observador a sentir algo que não faça parte do seu cotidiano e nem da sua existência corriqueira. $O$ sublime, talvez mais do que o belo, é o efeito máximo almejado pelo artista, pois é no sublime que o homem muitas vezes refaz suas perspectivas, suas visões acerca de si e do mundo que o cerca. A arte,

\footnotetext{
${ }^{8}$ ROHDEN, V. e MARQUES, A. apud KANT, Immanuel. Crítica da faculdade do juízo. Tradução de Valério Rohden e Antônio Marques. 2. ed. Rio de Janeiro: Forense Universitária, 1995, p. 69.

9 " $\mathrm{Al}$ contrario, el vivo sentimiento de lo bello se manifiesta por cierto esplendor brillante en los ojos, por la sonrisa, y muchas veces por una alegría estrepitosa. Alguna vez el sentimiento de lo sublime se halla acompañado de horror o de tristeza; en algunos casos de una tranquila admiración, y en otros se halla ligado al de una belleza extendida sobre un vasto plano. Yo llamaría la primera especie de sublime, lo sublime terrible, la segunda, sublime noble, y la tercera, sublime magnífico. Una profunda soledad es sublime, mas sublime terrible" (KANT, Immanuel. Observaciones sobre el sentimiento de lo bello y lo sublime. Edición bilingüe alemán-español. Traducción, estudio preliminar, notas e índice analítico Dulce María Granja. Madrid, FCE, Universidad Autónoma Metropolitana Iztapalapa, Universidad Nacional Autónoma de México, 2005, p. 86).

${ }^{10}$ REALE, Giovanni; ANTISERI, Dario. História da Filosofia: de Spinoza a Kant. Tradução de Ivo Storniolo. v. 4. São Paulo: Paulus, 2005, p. 425.
}

\begin{tabular}{|c|c|c|c|c|c|}
\hline intuitio & $\begin{array}{c}\text { ISSN } \\
1983-4012\end{array}$ & Porto Alegre & Vol.8 $-\mathrm{N}^{\circ} .2$ & $\begin{array}{c}\text { Dezembro } \\
2015\end{array}$ & p.146-158 \\
\hline
\end{tabular}


conforme inúmeros exemplos na história, possui de fato essa força de conduzir o ser humano ao sublime, ao sentimento de choque, violência, em um sentido mais refinado do termo.

A natureza, objeto de desejo a ser superado pelo homem, não se curva perante o anseio do homem, posto que maior que este, mas o homem tenta, apesar da sua condição de inferioridade, e a arte o auxilia nesse desejo, nesse sonho de superação da natureza, e para tamanha pretensão se enquadra o sublime, que conduz o homem a outras esferas do espírito, que o eleva do plano puramente material, físico, palpável, para outro, diverso, acima deste, cuja inclinação aos sentidos é manifesta. O outro plano ao qual nos referimos é o do supra-sensível:

O Sublime coloca-nos, pois, na presença de uma relação subjetiva direta entre a imaginação e a razão. Mas mais do que um acordo, esta relação é em primeiro lugar um desacordo, uma contradição vivida entre a exigência da razão e a potência da imaginação. E por isso que a imaginação parece perder a sua liberdade e o sentimento do sublime ser uma dor mais do que um prazer. Porém, no fundo do desacordo, surge o acordo; a dor torna possível um prazer. Quando a imaginação é posta na presença do seu limite por alguma coisa que a supera por todos os lados, ela mesma supera o seu próprio limite, é verdade que de maneira negativa, representando-se a inacessibilidade da Ideia racional e fazendo desta própria inacessibilidade algo de presente na natureza sensível (...) Tal é o acordo — discordante — da imaginação e da razão: não é apenas a razão que tem uma "destinação supra-sensível" mas também a imaginação. Neste acordo, a alma é sentida como a unidade supra-sensível indeterminada de todas as faculdades; somos nós próprios referidos a um foco, como a um "ponto de concentração" no supra-sensível ${ }^{11}$.

Como mediador entre o sensível e o suprassensível está o sublime, que exerce tão elevada função para o homem, reforçando, dessa forma, a sua ligação com uma forma específica de liberdade, a cosmológica, pois esta é uma liberdade que não se apresenta cerceada por qualquer espécie de lei. Mas esta liberdade que está intercalada com a questão moral e é melhor explicitada na terceira antinomia da primeira Crítica não será aqui aprofundada, apesar de que estética, liberdade e ética são muitas vezes apreendidas sob similar viés no pensamento kantiano. O que se configura como mais significativo nesse ponto é a possibilidade da liberdade, resultante do sublime, para o homem, uma vez que o sublime se encontra presente no espírito de cada ser humano. Dessa forma, afirma-se a questão da liberdade como algo interno ao homem, e no campo estético, é ela que possibilita o julgamento sobre o que o homem considera, ou não, sublime:

Pois, o verdadeiro sublime não pode estar contido em nenhuma forma sensível, mas concerne somente a ideias da razão, que, embora não possibilitem nenhuma

${ }^{11}$ DELEUZE, Gilles. A filosofia crítica de Kant. Tradução de Germiniano Franco. Lisboa/Portugal. Edições 70. 1963, p. 58.

\begin{tabular}{|c|c|c|c|c|c|}
\hline intuitio & $\begin{array}{c}\text { ISSN } \\
1983-4012\end{array}$ & Porto Alegre & Vol.8 $-\mathrm{N}^{\mathrm{o} .2}$ & $\begin{array}{c}\text { Dezembro } \\
2015\end{array}$ & p.146-158 \\
\hline
\end{tabular}


representação adequada a elas, são avivadas e evocadas ao ânimo precisamente por essa inadequação, que se deixa apresentar sensivelmente ${ }^{12}$.

Ao estabelecer uma distinção ente o sublime, na sua acepção mais verdadeira, do plano sensível, Kant também estrutura uma distinção entre arte e natureza, haja visto que a arte, como foi introduzido, está integrada com a liberdade. Ora, agir de modo livre é, de certo modo, utilizar-se da razão, pois é ela que situa o homem no plano das possibilidades de atuação. Praticar ou não uma ação, produzir ou não um quadro, ou um poema, enquadra-se facilmente na concepção de liberdade, esta que pode ser definida como o pensar independente de qualquer regra no sentido radical do termo, e no campo do juízo estético, o que prevalece referente à liberdade é o casuísmo do pensamento. A natureza não evoca essa questão da liberdade, algo que se apresenta claramente ante o pensamento de Kant.

\section{Arte, liberdade e natureza}

A rigor, dever-se-ia chamar de arte somente a produção mediante liberdade, isto é, mediante um arbítrio que põe a razão como fundamento de suas ações. Pois embora agrade denominar o produto das abelhas (os favos de cera construídos regularmente) uma obra de arte, isto, contudo ocorre somente devido à analogia com a arte; tão logo nos recordemos que elas não fundam o seu trabalho sobre nenhuma ponderação racional própria, dizemos imediatamente que se trata de um produto da natureza (do instinto) e enquanto arte é atribuída somente a seu criador ${ }^{13}$.

Essa distinção entre arte e natureza, aparentemente evidente, encerra em si todo um jogo de raciocínios que não pode ser ignorado pelo homem, principalmente no plano do estético, uma vez que muitos indivíduos por vezes equivalem ambas como se fossem uma coisa só. A representação de um cavalo em um quadro é completamente diversa da imagem visual do mesmo cavalo que, se pudesse ser colocado imóvel na mesma posição em que foi representado na tela, causaria efeito diverso em quem o observa nos dois momentos. Ao homem, é preciso estar absolutamente clara a distinção do que é arte e o que vem a ser natureza.

A razão aciona a arte, assim como o seu inverso. Para a criação de uma escultura, por exemplo, é preciso um raciocínio que, em um primeiro momento, se aproprie da natureza para a efetivação do objeto de arte. Apropriar-se não equivale dizer que são a mesma coisa. Uma ação do homem sobre a natureza é prontamente percebida por outro homem: certa disposição de pedras em uma praia, que resulte em um

${ }^{12}$ KANT, Immanuel. Crítica da faculdade do juízo. Tradução de Valério Rohden e Antônio Marques. 2. ed. Rio de Janeiro: Forense Universitária, 1995, p. 91.

${ }^{13}$ KANT, Immanuel. Crítica da faculdade do juízo. Tradução de Valério Rohden e Antônio Marques. 2. ed. Rio de Janeiro: Forense Universitária, 1995, p. 149.

\begin{tabular}{|c|c|l|l|c|c|}
\hline intuitio & $\begin{array}{c}\text { ISSN } \\
1983-4012\end{array}$ & Porto Alegre & Vol.8 $-\mathrm{N}^{\mathrm{o}} .2$ & $\begin{array}{c}\text { Dezembro } \\
2015\end{array}$ & p.146-158 \\
\hline
\end{tabular}


símbolo qualquer, que por sua vez possua uma representatividade social é de imediato compreendido por quem o vê.

A arte é um produto da capacidade técnica do homem, e não apenas no sentido inspirador. É através da arte que o homem se projeta no mundo, assimilando-o e tentando dominá-lo. E nesse aspecto, Kant faz outro alerta: a arte não é ciência:

A arte, enquanto habilidade do homem, também se distingue da ciência (o poder distingue-se do saber), assim como faculdade prática distingue-se de faculdade teórica, e técnica distingue-se da teoria (como agrimensura distingue-se da geometria) ${ }^{14}$.

A capacidade de conhecer como um produto é confeccionado não dá a mínima garantia que aquele saber, por exemplo, virá a produzir o objeto do qual possui todo o conhecimento teórico. É nesse sentido que arte e ciência se distinguem. $\mathrm{Na}$ arte não existe o certo ou o errado, algo que somente ocorre se for conveniente para a estética, ao contrário da ciência, que define com exatidão os seus parâmetros dentro das possibilidades de erro ou acerto, de falso ou verdadeiro. A arte, se vista sob um ângulo mais dualista, enquadra-se nesse esquema científico somente no plano das sensações que causa no homem, ou seja, prazer e desprazer. É por isso que não existe ciência estética, pois não existe uma ciência subjetiva, baseada unicamente no sujeito.

Sem ainda decidir nada sobre a possibilidade dessa vinculação, não se pode deixar de reconhecer já aqui uma certa adequação do juízo ao sentimento de prazer, para servir de fundamento-de-determinação a este ou encontrá-lo nele, nesta medida: que, se na divisão da faculdade-de-conhecimento por conceitos entendimento e razão referem suas representações a objetos, para obter conceitos deles, o Juízo se refere exclusivamente ao sujeito e por si só não produz nenhum conceito de objetos ${ }^{15}$.

O conceito na ciência deve ser fechado, não uma noção. O que o cientista elabora deve estar fixo em uma conceituação que dê conta de todas as possibilidades da sua teoria acerca de um determinado fenômeno. $\mathrm{O}$ artista, por sua vez, cria formas que nunca se repetem, que não podem ser fixadas sob um conceito determinado em um molde científico, mas particular, próprio. No juízo estético o que prevalece é o casuísmo do pensamento:

(...) cada arte pressupõe regras, através de cuja fundamentação de um produto, se ele deve chamar-se artístico, é pela primeira vez representado como possível. $\mathrm{O}$ conceito de bela arte, porém, não permite que o juízo de seu produto seja deduzido de qualquer regra que tenha um conceito como fundamento

\footnotetext{
${ }^{14}$ KANT, Immanuel. Crítica da faculdade do juízo. Tradução de Valério Rohden e Antônio Marques. 2. ed. Rio de Janeiro: Forense Universitária, 1995, p. 149.

${ }^{15}$ KANT, Immanuel. Crítica da faculdade do juízo. Tradução de Valério Rohden e Antônio Marques. 2. ed. Rio de Janeiro: Forense Universitária, 1995, p. 43.
}

\begin{tabular}{|c|c|c|c|c|c|}
\hline intuitio & $\begin{array}{c}\text { ISSN } \\
1983-4012\end{array}$ & Porto Alegre & Vol.8 $-\mathrm{N}^{\circ} .2$ & $\begin{array}{c}\text { Dezembro } \\
2015\end{array}$ & p.146-158 \\
\hline
\end{tabular}


determinante, por conseguinte que ponha como fundamento um conceito da maneira como ele é possível. Portanto, a própria arte bela não pode ter ideia da regra segundo a qual ela deva realizar o seu produto. Ora, visto que sem uma regra que o anteceda um produto jamais pode chamar-se arte, assim a natureza do sujeito (e pela disposição da faculdade do mesmo) tem que dar a regra à arte, isto é, a bela arte somente é possível como um produto do gênio ${ }^{16}$.

\section{Gênio e natureza}

Artista e gênio são colocados sob similar patamar na obra kantiana, uma vez que o gênio seria o responsável pela criação do belo em sentido artístico, cuja representação, deve sempre lembrar, está associada à natureza, não de modo caótico, mas harmônico:

Gênio é o talentoso (dom natural) que dá toda regra à arte. Já que o próprio talento enquanto faculdade produtiva inata do artista pertence à natureza, também se poderia expressar assim: Gênio é a inata disposição de ânimo (ingenium) pela qual a natureza dá a regra à arte ${ }^{17}$.

A relação que Kant enfatiza entre artista e natureza se dá pela concepção de que a primeira é uma representação da segunda, como abordado anteriormente, uma vez que a arte se apresenta como um produto de qualidade artística quando da sua imersão na natureza como fonte inspiradora, possibilitando, dessa forma, a aparência de naturalidade que a arte deve apresentar, ou seja, a arte deve transparecer naturalidade, como se fizesse parte da natureza, apesar de, efetivamente, não fazer.

O gênio, como explicita Kant, é aquele que produz algo para o qual não pode fornecer nenhuma regra determinada, o que significa dizer que o gênio deve manter o sentido de originalidade na sua obra. O artista, ao trabalhar com a matéria que lhe servirá como instrumento para sua expressão artística, como as tintas, incute nesses e em outros materiais, como a tela, a sua habilidade, cuja técnica não está prevista em qualquer conceituação conforme os ditames científicos. $\mathrm{O}$ que se pode dizer que motiva o artista na sua produção é a ideia pré-concebida que possuiu da obra de arte que irá produzir. Essa ideia ganha forma com o pincel, as tintas e a tela, contudo não se pode afirmar que o gênio está seguindo determinadas regras na construção do produto artístico, ele é livre, e a razão não o abandona na elaboração do seu ofício.

A liberdade do gênio se faz presente no fato de que ao traçar linhas que compõe o seu desenho, o artista pode seguir em direções similares, ou opostas, ou trançadas, conforme o seu desejo. A natureza, nesse processo aparentemente caótico do artista, é aquela que é acionada como cerne do processo artístico,

${ }^{16}$ KANT, Immanuel. Crítica da faculdade do juízo. Tradução de Valério Rohden e Antônio Marques. 2. ed. Rio de Janeiro: Forense Universitária, 1995, p. 149.

${ }^{17}$ KANT, Immanuel. Crítica da faculdade do juízo. Tradução de Valério Rohden e Antônio Marques. 2. ed. Rio de Janeiro: Forense Universitária, 1995, p. 181.

\begin{tabular}{|c|c|c|c|c|c|}
\hline intuitio & $\begin{array}{c}\text { ISSN } \\
1983-4012\end{array}$ & Porto Alegre & Vol.8- No.2 & $\begin{array}{c}\text { Dezembro } \\
2015\end{array}$ & p.146-158 \\
\hline
\end{tabular}


pois será ela que figurará como fonte para o gênio, que por sua vez produzirá algo que oscila entre o conhecido e o desconhecido: conhecido pelo fato de que é inspirado na natureza; desconhecido justamente pelo pressuposto de que não é algo constituinte da natureza, ou seja, dela não faz parte:

Mas, visto que o gênio é um favorito da natureza, que somente se pode presenciar como aparição rara, assim o seu exemplo produz para outros bons cérebros uma escola, isto é, um ensinamento metódico segundo regras, na media em que se tenha podido extraí-lo daqueles produtos do espírito e de sua peculiaridade; e nesta medida a arte bela é para essas uma imitação para a qual a natureza deu através de um gênio a regra ${ }^{18}$.

A imaginação do gênio não é autônoma, prescinde da natureza para a efetivação do trabalho artístico. Há, entre ambos, a sujeição do primeiro em relação à segunda. É essa natureza que, de modo bastante singular, fornecerá ao gênio as regras necessárias para que o artista possa criar formas. O homem, assim posto, é submetido à natureza que, como dito anteriormente, tenta submetê-la, mas não consegue, restando à arte a impressão, mesmo que idealizada artisticamente, de que o homem apresenta uma hegemonia em relação à natureza.

\section{Considerações finais}

A arte está desatrelada dos valores morais. Um quadro não pode ser apreciado sob a insígnia do certo ou do errado. Se isto ocorrer, pode-se afirmar que não está se efetuando a experiência estética, esta que, como visto, é desinteressada e tem como objetivo o prazer, ou desprazer. Dessa forma, a experiência estética possui um fim em si mesma.

A contemplação do objeto artístico não possuiu uma finalidade aparente, definida sob os padrões de utilitarismo. Mas isso não significa dizer que o objeto apreciado e que a experiência artística não possuem valor algum, não servem para nada, ao contrário, existe, de fato, um interesse que não pode ser vinculado a benefícios, ou que não podem ser vinculados aos padrões que rotineiramente são estabelecidos no caráter da praticidade.

O belo, presente na obra de arte, afeta o homem de modo bastante singular, chegando até mesmo a sensações desconfortantes, é o que se chamará prazer, ou desprazer, na relação entre objeto de arte e o sujeito. Kant dedicou-se ao estudo sobre o que, de fato, é o belo na obra de arte e de que forma ele atua sobre o homem, levando-se em conta o plano da natureza e da liberdade, sob a forma do estético.

\footnotetext{
${ }^{18}$ KANT, Immanuel. Crítica da faculdade do juízo. Tradução de Valério Rohden e Antônio Marques. 2. ed. Rio de Janeiro: Forense Universitária, 1995, 164.
}

\begin{tabular}{|c|c|c|c|c|c|}
\hline intuitio & $\begin{array}{c}\text { ISSN } \\
1983-4012\end{array}$ & Porto Alegre & Vol.8 $-\mathrm{N}^{\circ} .2$ & $\begin{array}{c}\text { Dezembro } \\
2015\end{array}$ & p.146-158 \\
\hline
\end{tabular}




\section{Referências}

BENJAMIN, Walter. "A obra de arte na era de sua reprodutibilidade”. In: Magia e Técnica, arte e política - ensaios sobre literatura e história da cultura. Obras escolhidas, volume I, $2^{\mathrm{a}}$ edição, São Paulo: Editora Brasiliense, 1994. DELEUZE, Gilles. A filosofia crítica de Kant. Tradução de Germiniano Franco. Lisboa/Portugal. Edições 70. 1963. pp. 113-136.

, A ideia de gênese estética em Kant, 1963. Revue d'esthétique, v. XVI, nº 2, abril-junho, Paris, PUF, 1963,

KANT, Immanuel. Crítica da faculdade do juízo. Tradução de Valério Rohden e Antônio Marques. 2. ed. Rio de Janeiro: Forense Universitária, 1995.

, Observaciones sobre el sentimiento de lo bello y lo sublime. Edición bilingüe alemán-español. Traducción, estudio preliminar, notas e índice analítico Dulce María Granja. Madrid, FCE, Universidad Autónoma Metropolitana Iztapalapa, Universidad Nacional Autónoma de México, 2005.

REALE, Giovanni; ANTISERI, Dario. História da Filosofia: de Spinoza a Kant. Tradução de Ivo Storniolo. v. 4. São Paulo: Paulus, 2005.

TERRA, R. "Entre as poéticas prescritivas e as estéticas filosóficas" In: Passagens - estudos sobre a filosofia de Kant. Rio de Janeiro: UFRJ, 2003.

Recebido em: 07/10/2014

Aprovado para publicação em: 29/09/2015

\begin{tabular}{|l|c|l|l|c|c|}
\hline intuitio & $\begin{array}{c}\text { ISSN } \\
1983-4012\end{array}$ & Porto Alegre & Vol.8 $-\mathrm{N}^{\circ} .2$ & $\begin{array}{c}\text { Dezembro } \\
2015\end{array}$ & p.146-158 \\
\hline
\end{tabular}

